\title{
Serum IGFBP-3 is a more effective predictor than IGF-1 and IGF-2 for the development of hepatocellular carcinoma in patients with chronic HCV infection
}

\author{
EIMAN ALEEM ${ }^{1}$, AYMAN ELSHAYEB $^{2}$, NIHAL ELHABACHI ${ }^{3}$, \\ AMAL REFAAT MANSOUR ${ }^{4}$, AHMED GOWILY $^{5}$ and ASMAA HELA ${ }^{1}$ \\ ${ }^{1}$ Molecular Biology Division, Zoology Department, Faculty of Science; \\ Departments of ${ }^{2}$ Tropical Medicine, ${ }^{3}$ Physiology, ${ }^{4}$ Clinical Pathology and \\ ${ }^{5}$ Clinical Oncology and Nuclear Medicine, Faculty of Medicine, Alexandria University, Alexandria, Egypt
}

Received October 25, 2011; Accepted December 19, 2011

DOI: $10.3892 / \mathrm{ol} .2011 .546$

\begin{abstract}
Hepatocellular carcinoma (HCC) contributes to $14.8 \%$ of all cancer mortality in Egypt, which has a high prevalence of hepatitis $\mathrm{C}$ virus (HCV). We have previously shown alterations in the insulin-like growth factor-1 (IGF-1) receptor signalling pathway during experimental hepatocarcinogenesis. The aim of this study was to determine whether serum levels of IGF-1, IGF-2 and IGFBP-3 can be used to discriminate between HCC and the stages of hepatic dysfunction in patients with liver cirrhosis assessed by the Child-Pugh (CP) score, and to correlate these levels with HCC stages. We recruited 241 subjects to the present study; 79 with liver cirrhosis, 62 with HCV-induced HCC and 100 age-matched controls. Results showed that serum levels of IGF-1, IGF-2 and IGFBP-3 were reduced significantly in cirrhosis and HCC patients in comparison to the controls, and that this reduction negatively correlated with the CP scores. However, only IGFBP-3 levels showed significant negative correlation with $\alpha$-fetoprotein levels. The reduction in IGF-1 and IGFBP-3 but not IGF-2 levels was significant in HCC in comparison to patients with cirrhosis. None of the parameters significantly correlated with the HCC stage. IGFBP-3 levels
\end{abstract}

Correspondence to: Dr Eiman Aleem, Molecular Biology Division, Zoology Department, Faculty of Science, Alexandria University, Moharram Bey 21511, Alexandria, Egypt

E-mail: eiman.aleem@ki.se

\section{Abbreviations:}

IGF-1, insulin-like growth factor-1; IGF-2, insulin-like growth factor-2; IGFBP-3, insulin-like growth factor binding protein-3; IGF-1R, insulin-like growth factor-1 receptor; $\mathrm{GH}$, growth hormone; $\mathrm{HCV}$, hepatitis $\mathrm{C}$ virus; $\mathrm{HCC}$, hepatocellular carcinoma; $\mathrm{CP}$, ChildPugh score; AFP, $\alpha$-fetoprotein; ROC, receiver operating curve; AUC, area under the ROC curve

Key words: hepatitis C virus, cirrhosis, insulin-like growth factor-1, insulin-like growth factor-2, insulin-like growth factor binding protein-3, hepatocellular carcinoma, Egypt, biomarker discriminated between cirrhosis and $\mathrm{HCC}$ at a sensitivity of $87 \%$, a specificity of $80 \%$ and a cut-off value of $<682.6 \mathrm{ng} /$ $\mathrm{ml}$. In conclusion, although our results showed that serum IGF-1, IGF-2 and IGFBP-3 are reduced with the progression of hepatic dysfunction, only IGFBP-3 may be considered as the most promising serological marker for the prediction of the development of $\mathrm{HCC}$ in the chronic $\mathrm{HCV}$ patients with liver cirrhosis.

\section{Introduction}

Hepatocellular carcinoma (HCC) is the third most common cause of cancer mortality worldwide (1). It contributes to $14.8 \%$ of all cancer mortality in Egypt, with a higher incidence in males $(17.3 \%)$ than in females $(11.5 \%)$. It is the second most frequent cancer type in Egyptian males after bladder cancer and the eighth most frequent in Egyptian females (2). The high incidence of $\mathrm{HCC}$ in Egypt is attributed to the high prevalence of hepatitis $\mathrm{C}$ virus (HCV). HCV is currently the most significant public health problem in Egypt with an overall prevalence of $17.4 \%$ in males and $12.2 \%$ in females, and it increases with age to a prevalence of $39.4 \%$ in 55-59-year olds (3). Chronic hepatitis usually leads to the sequential occurrence of liver fibrosis and cirrhosis with a high risk of development of HCC. It has been estimated that $20 \%$ of HCV-infected patients develop liver cirrhosis and approximately $40 \%$ of these develop HCC within 10-15 years (4).

The insulin-like growth factor (IGF) signalling system is an essential regulator of growth and development. IGF-1 has a strong effect on cell proliferation and differentiation and is a potent inhibitor of apoptosis (5). We previously showed that during experimental hepatocarcinogenesis the IGF-1 receptor (IGF-1R), which mediates IGF-1 and IGF-2 signals, and its downstream proteins are initially overexpressed in preneoplastic foci, which may reflect that hepatocytes in their early stage of transformation are more sensitive to stimulation by circulatory IGFs. This overexpression is gradually reduced in later stages, and it is almost completely lost in poorly differentiated HCC $(6,7)$, which may indicate an IGF-independent state. The liver is the major site of IGF-1 production (8). Serum 
IGF-1 levels are influenced by many factors including age and nutrition, but growth hormone $(\mathrm{GH})$ is the principal regulator of IGF-1 production in the liver and secretion into the blood stream. IGF-2 is produced in various tissues throughout life. Serum concentration of IGF-2 remains stable following puberty, and is not regulated by GH (9). The bioavailability of IGFs is modulated by high-affinity binding proteins known as insulinlike growth factor binding proteins (IGFBPs) (from 1 to 7 ), of which the liver is a significant source. Most of the IGF-1 in circulation is bound by IGFBP-3, whose circulating levels are more than 10-fold higher than any of the other binding proteins (10). Several studies have reported the reduction of serum IGF-1 levels associated with the development of human HCC from cirrhosis $(11,12)$, the increase of IGF-2 levels in HCC (13), and the reduction of IGFBP-3 levels in liver cirrhosis in comparison to healthy subjects $(14,15)$.

Patients with liver cirrhosis should be carefully monitored for the early detection of HCC. Currently, surveillance for HCC development is based on a six-month $\alpha$-fetoprotein (AFP) determination and ultrasound examination. However, AFP levels do not discriminate between benign liver disease and HCC. Additionally, they have poor sensitivity and specificity (16) and vary with the etiology of liver disease, treatment and tumor stage (17). Therefore, it is of utmost importance to identify sensitive biomarkers that allow the prediction of HCC development at an early stage, and predict the severity of cirrhosis stage, and at the same time are easily measurable and minimally invasive (18).

The present study was carried out to i) investigate whether serum levels of IGF-1, IGF-2 and IGFBP-3 may be used to discriminate between the stages of hepatic dysfunction in Egyptian patients with liver cirrhosis assessed by Child-Pugh (CP) score, and subsequently ii) whether they may be used individually or in combination as biomarkers for the development of $\mathrm{HCC}$ in patients with liver cirrhosis and to correlate the levels with the HCC stage and other standard HCC biomarkers such as AFP.

\section{Materials and methods}

Patients. A total of 241 subjects were recruited into the present study between March 2010 and April 2011 at the Faculty of Medicine, Alexandria University Hospital. The subjects were divided into three groups: group I included 79 patients with chronic HCV and liver cirrhosis. This group was further subdivided into three subgroups according to the $\mathrm{CP}$ score system (11 patients with CP A, male/female $=5 / 6,29$ patients with CP B, male/female $=14 / 15$ and 39 patients with CP C, male $/$ female $=19 / 20)$. Group II included 62 patients with HCC in addition to HCV-induced liver cirrhosis (male/female $=48 / 14$ ). Group III included 100 healthy volunteers as controls (male/ female $=40 / 60)$ (Table I). For all subjects, height and weight were measured and the body mass index (BMI) was calculated as body weight in kilograms divided by the square of height in meters $\left(\mathrm{kg} / \mathrm{m}^{2}\right)$. Subjects with BMI $>30$, with a history of alcohol abuse, heart disease, kidney disease, diabetes mellitus, endocrine-related diseases, tobacco-related cancers and hepatitis B virus infection were excluded from the study. At the time of enrolment, the patients were evaluated for complete medical history and physical examination. Ultrasound of the liver, liver functions and complete blood picture (CBC), serum albumin, serum bilirubin and prothrombin time were performed for all patients. Screening for $\mathrm{HCV} \mathrm{Ab}$ was performed routinely using an ELISA assay, and confirmed by PCR according to Kato et al (19). In the present study, the HCC staging followed the Barcelona Clinic Liver Cancer (BCLC) staging system.

Ethical approval. All patients and healthy controls who participated in the present study signed an informed consent form. The study protocol was approved by the Ethics Committee of the Faculty of Medicine, Alexandria University, Egypt and is in accordance with the Helsinki Declaration of 1975.

Sample collection, determination of glucose and AFP. Venous blood ( $5 \mathrm{ml}$ ) was withdrawn from the subjects following $12 \mathrm{~h}$ overnight fasting. Serum fasting blood glucose was measured immediately for all subjects with a Cobas Integra 400 analyzer (Roche Diagnostics, USA). AFP was measured using a Siemens ADVIA Centaur analyzer (Siemens Healthcare Diagnostics, Germany). Serum samples were then stored at $-80^{\circ} \mathrm{C}$ until use.

Quantitative detection of serum IGF-1, IGF-2, and IGFBP-3. Serum IGF-I, IGF-2 and IGFBP-3 were measured using the following ELISA kits according to the manufacturer's instructions: IGF-1 ELISA kit (DRG International, USA), IGF-2 active non-extraction ELISA kit (Diagnostic Systems Laboratories, USA) and IGFBP-3 Quantikine ELISA Kit (R\&D Systems, USA). Absorbance was read at $450 \mathrm{~nm}$ for the three kits in a microplate reader.

Statistical analysis. Statistical analysis was performed using the SPSS statistical package version 16.00 (SPSS Inc, Chicago, IL, USA). Data were expressed as the mean \pm standard deviation. A receiver operating curve (ROC) was used to establish the cut-off values that provided the maximal diagnostic accuracy. Positive and negative predictive values were also determined for each of the following parameters; IGF-1, IGF-2, IGFBP-3, IGF-1 and IGF-2, IGF-1 and IGFBP-3, IGF-2 and IGFBP-3 in predicting HCC. $\mathrm{P}<0.05$ was considered statistically significant.

\section{Results}

Subjects. The present study was conducted on 241 subjects divided into three groups: group I included patients with chronic HCV and liver cirrhosis $(n=79)$, group II included patients with $\mathrm{HCC}$ developed from $\mathrm{HCV}$-induced cirrhosis $(n=62)$, and group III included healthy subjects $(n=100)$. Clinical characteristics of the subjects are shown in Table I. Group I was classified into 11 patients with CP A (mean score $5.66 \pm 0.49), 29$ patients with CP B (mean score 8.22 \pm 0.84 ) and 39 patients with CP C (mean score 11.62 \pm 1.11 ). No significant difference was found between the three subgroups in terms of age, BMI and glucose levels (Table I). Similarly, there were no significant differences in these parameters between patients with cirrhosis and healthy subjects (group III), and HCC patients (group II), and between groups II (HCC) and III (controls), respectively ( $\mathrm{p}>0.05)$.

AFP levels in the study groups. The mean AFP levels were $3.5 \pm 1.9,110 \pm 227.1$ and $207 \pm 257.4 \mathrm{ng} / \mathrm{ml}$ in the healthy 
Table I. Clinical characteristics of the subjects enrolled in the present study.

\begin{tabular}{|c|c|c|c|c|c|c|}
\hline \multirow{3}{*}{$\begin{array}{l}\text { Clinical } \\
\text { parameters }\end{array}$} & \multicolumn{3}{|c|}{ Group I } & \multirow{3}{*}{ 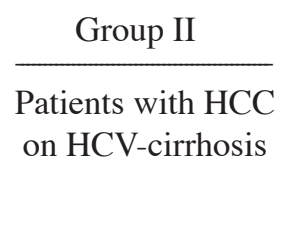 } & \multirow{3}{*}{$\frac{\text { Group III }}{\text { Healthy subjects }}$} & \multirow{3}{*}{ P-value } \\
\hline & \multicolumn{3}{|c|}{$\begin{array}{l}\text { Patients with HCV-cirrhosis } \\
\qquad(n=79)\end{array}$} & & & \\
\hline & CP A & CP B & $\mathrm{CPC}$ & & & \\
\hline $\begin{array}{l}\text { No. of subjects } \\
\text { (\% from total) }\end{array}$ & $\begin{array}{r}11 \\
(13.9)\end{array}$ & $\begin{array}{r}29 \\
(36.7)\end{array}$ & $\begin{array}{r}39 \\
(49.4)\end{array}$ & 62 & 100 & \\
\hline $\begin{array}{l}\text { Age (years) } \\
(\text { Mean } \pm \text { SD) }\end{array}$ & $\begin{array}{l}47.5 \\
\pm 4.9\end{array}$ & $\begin{array}{l}46.7 \\
\pm 6.3\end{array}$ & $\begin{array}{l}46.8 \\
\pm 6.8\end{array}$ & $48.7 \pm 4.6$ & $46.8 \pm 6.7$ & 0.1 \\
\hline $\begin{array}{l}\text { BMI } \\
(\text { Mean } \pm \mathrm{SD})\end{array}$ & $\begin{array}{l}24.3 \\
\pm 0.6\end{array}$ & $\begin{array}{r}24.7 \\
\pm 0.8\end{array}$ & $\begin{array}{l}24.8 \\
\pm 0.6\end{array}$ & $25.1 \pm 2.3$ & $24.7 \pm 2.3$ & 0.3 \\
\hline $\begin{array}{l}\text { Blood glucose }(\mathrm{mg} / \mathrm{dl}) \\
(\text { Mean } \pm \text { SD })\end{array}$ & $\begin{array}{r}90.5 \\
\pm 14.6\end{array}$ & $\begin{array}{r}91.3 \\
\pm 18.9\end{array}$ & $\begin{array}{r}85.8 \\
\pm 19.5\end{array}$ & $91.7 \pm 17.5$ & $90.6 \pm 10.5$ & 0.4 \\
\hline
\end{tabular}

Number of subjects in each of the three main groups (cirrhosis, HCC and control) and the three subgroups of patients with cirrhosis classified according to the Child-Pugh score into CP A, CP B and CP C, their age, body mass index and glucose levels are shown. HCV, hepatitis C virus; HCC, hepatocellular carcinoma; CP A, Child-Pugh score A; CP B, Child-Pugh score B; CP C, Child-Pugh score C; SD, standard deviation; BMI, body mass index. ${ }^{\text {a }}$ ignificant at $\mathrm{p} \leq 0.05$.

subjects, patients with cirrhosis and HCC patients, respectively (Table II). These values were significant between patients with cirrhosis and control subjects, HCC and control subjects, as well as between cirrhosis and HCC patients. Furthermore, we measured AFP levels in each of the three cirrhosis subgroups of group I, which were 51.73 $\pm 108.8,127.6 \pm 248.8$ and $114 \pm 236.2 \mathrm{ng} / \mathrm{ml}$ in CP A, CP B and CP C, respectively (Table III). No significant difference was observed in the AFP values in patients with cirrhosis classified according to CP scores $(\mathrm{p}>0.05)$.

Serum IGF-1, IGF-2 and IGFBP-3 levels are reduced in cirrhosis and HCC patients. In the present study, serum levels of IGF-1, IGF-2 and IGFBP-3 were measured in each of the three groups (patients with cirrhosis, with $\mathrm{HCC}$ and healthy subjects) (Table II, Fig. 1). The levels in the normal subjects were $394.7 \pm 60.2,2197.5 \pm 499.9$ and $3131.4 \pm 1159.7 \mathrm{ng} / \mathrm{ml}$ for IGF-1, IGF-2 and IGFBP-3, respectively. IGF-1 levels were found to be significantly reduced in cirrhosis $(249 \pm 131 \mathrm{ng} /$ $\mathrm{ml})$ and in HCC patients $(166.7 \pm 121.4 \mathrm{ng} / \mathrm{ml})$ in comparison to healthy subjects. The reduction of IGF-1 levels was also statistically significant between cirrhosis and HCC patients. Similarly, serum IGF-2 levels decreased significantly in cirrhosis $(649.1 \pm 473.4 \mathrm{ng} / \mathrm{ml})$ and in HCC patients $(549 \pm 405 \mathrm{ng} / \mathrm{ml})$ in comparison to healthy subjects; however, there was no significant difference between IGF-2 levels in patients with cirrhosis and those with HCC. Serum IGFBP-3 levels followed the same pattern with a significant reduction in cirrhosis $(1474.3 \pm 1042.2 \mathrm{ng} / \mathrm{ml})$ and in HCC patients $(456.2 \pm 268 \mathrm{ng} /$ $\mathrm{ml}$ ) in comparison to healthy subjects. The reduction in serum IGFBP-3 levels was significant between control and cirrhosis patients, control and HCC patients, as well as between cirrhosis and HCC patients $(\mathrm{p} \leq 0.05)$ (Table II, Fig. 1). In the present study, the majority of the HCC patients enrolled were either in the intermediate stage B $(44 \%)$ or advanced stage C (39\%), fewer were in the early stage A $(5 \%)$ or in the terminal stage D (12\%). IGFBP-3 levels showed a negative correlation with tumor stage, which was not statistically significant $(\mathrm{p}>0.05)$.

Serum IGF-1, IGF-2 and IGFBP-3 levels negatively correlated with $C P$ score. The mean serum levels of IGF-1, IGF-2 and IGFBP-3 in the three CP stages of HCV-induced cirrhosis in Egyptian patients are shown in Table III. For IGF-1 and IGF-2 there was a significant reduction in serum levels between $\mathrm{CP}$ A and B, CP A and C, as well as between CP B and $\mathrm{C}$, respectively. However, IGFBP-3 levels were reduced significantly between $\mathrm{CP} A$ and $\mathrm{C}$, and between $\mathrm{B}$ and $\mathrm{C}$, but not between $\mathrm{A}$ and $\mathrm{B}$. The negative correlation between the CP score and IGF-1 ( $\mathrm{r}=-0.51)$, IGF-2 ( $\mathrm{r}=0.58)$ and IGFBP-3 levels $(\mathrm{r}=0.63)$, respectively, is shown in Fig. $2 \mathrm{~A}-\mathrm{C}(\mathrm{p} \leq 0.05)$. Furthermore, the serum levels of IGF-1 and IGF-2 were found to be significantly lower in HCC patients than those with $\mathrm{CP} A$ and B liver cirrhosis ( $\mathrm{p} \leq 0.05)$. However, no significant difference was observed between IGF-1 and IGF-2 levels in HCC cases and those with CP C stage of liver cirrhosis $(p=0.16)$. By contrast, the mean levels of IGFBP-3 were significantly lower in HCC patients than the mean levels of CP A, B and C patients, respectively $(\mathrm{p} \leq 0.05)$.

IGFBP-3 levels negatively correlate with AFP in liver cirrhosis, but not in HCC patients. As we propose the serum levels of IGF-1, IGF-2 and IGFBP-3 to be markers for progression of hepatic dysfunction and development of HCC in patients with cirrhosis, we studied whether there is a correlation between their levels and those of the well-established HCC marker AFP. A significant negative correlation was found only between IGFBP-3 and AFP in patients with liver cirrhosis $(r=-0.32$, $\mathrm{p}=0.03$ ) (Fig. 2D). By contrast, no significant difference was found between the levels of IGF-1 and IGF-2 and AFP in the same group of patients. Furthermore, no correlation was found 
Table II. Serum levels of IGF-1, IGF-2, IGFBP-3 and $\alpha$-fetoprotein in patients with cirrhosis, HCC and healthy subjects.

\begin{tabular}{|c|c|c|c|c|c|}
\hline & Group I & Group II & Group III & & \\
\hline & $\begin{array}{c}\text { Cirrhosis patients } \\
\qquad(\mathrm{n}=79)\end{array}$ & $\begin{array}{l}\text { HCC patients } \\
\quad(n=62)\end{array}$ & $\begin{array}{l}\text { Healthy subjects } \\
\qquad(n=100)\end{array}$ & & groups $^{\mathrm{a}}$ \\
\hline $\begin{array}{l}\text { IGF-1 } \\
(\mathrm{ng} / \mathrm{dl})\end{array}$ & $249 \pm 131$ & $166.7 \pm 121.4$ & $394.7 \pm 60.2$ & $97.39^{\mathrm{a}}$ & $\begin{array}{c}\text { I, III } \\
\text { II, III } \\
\text { I, II }\end{array}$ \\
\hline $\begin{array}{l}\text { IGF-2 } \\
(\mathrm{ng} / \mathrm{dl})\end{array}$ & $649.1 \pm 473.4$ & $549 \pm 405$ & $2197.5 \pm 499.9$ & $334.7^{\mathrm{a}}$ & $\begin{array}{l}\text { I, III } \\
\text { II, III }\end{array}$ \\
\hline $\begin{array}{l}\text { IGFBP-3 } \\
(\mathrm{ng} / \mathrm{dl})\end{array}$ & $1474.3 \pm 1042.2$ & $456.2 \pm 268$ & $3131.4 \pm 1159.7$ & $100.6^{\mathrm{a}}$ & $\begin{array}{c}\text { I, III } \\
\text { II, III } \\
\text { I, II }\end{array}$ \\
\hline $\begin{array}{l}\text { AFP } \\
(\mathrm{ng} / \mathrm{dl})\end{array}$ & $110 \pm 227.1$ & $207 \pm 257.4$ & $3.5 \pm 1.9$ & $11.5^{\mathrm{a}}$ & $\begin{array}{c}\text { I, III } \\
\text { II, III } \\
\text { I, II }\end{array}$ \\
\hline
\end{tabular}

IGF-1, insulin-like growth factor-1; IGF-2, insulin-like growth factor-2; IGFBP-3, insulin-like growth factor binding protein-3; AFP,

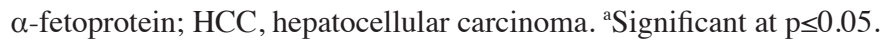

Table III. Serum levels of IGF-1, IGF-2 and IGFBP-3 and $\alpha$-fetoprotein in patients with cirrhosis classified according to Child-Pugh scores into A, B and C.

\begin{tabular}{|c|c|c|c|c|c|}
\hline & \multicolumn{3}{|c|}{ Group I } & \multirow[b]{2}{*}{$\mathrm{F}$ test } & \multirow[b]{2}{*}{ Significance between groups ${ }^{\mathrm{a}}$} \\
\hline & $\begin{array}{l}\text { Child-Pugh A } \\
\quad(\mathrm{n}=11)\end{array}$ & $\begin{array}{l}\text { Child-Pugh B } \\
\quad(n=29)\end{array}$ & $\begin{array}{l}\text { Child-Pugh C } \\
\qquad(\mathrm{n}=39)\end{array}$ & & \\
\hline $\begin{array}{l}\text { IGF-1 } \\
(\mathrm{ng} / \mathrm{ml})\end{array}$ & $377.3 \pm 71.7$ & $268.5 \pm 100.2$ & $198.5 \pm 138.3$ & $11.5^{\mathrm{a}}$ & $\begin{array}{l}\text { CP A, B } \\
\text { CP A, C } \\
\text { CP B, C }\end{array}$ \\
\hline $\begin{array}{l}\text { IGF-2 } \\
(\mathrm{ng} / \mathrm{ml})\end{array}$ & $1179.5 \pm 575.8$ & $736.9 \pm 413.6$ & $435.2 \pm 329.9$ & $17.1^{\mathrm{a}}$ & $\begin{array}{l}\mathrm{CP} \mathrm{A}, \mathrm{B} \\
\mathrm{CP} \mathrm{A}, \mathrm{C} \\
\mathrm{CP} \mathrm{B}, \mathrm{C}\end{array}$ \\
\hline $\begin{array}{l}\text { IGFBP-3 } \\
(\mathrm{ng} / \mathrm{ml})\end{array}$ & $2638.6 \pm 919.2$ & $1891.5 \pm 1148.4$ & $853.4 \pm 396.9$ & $14.6^{\mathrm{a}}$ & $\begin{array}{l}\text { CP A, C } \\
\text { CP B, C }\end{array}$ \\
\hline $\begin{array}{l}\text { AFP } \\
(\mathrm{ng} / \mathrm{ml})\end{array}$ & $51.73 \pm 108.8$ & $127.6 \pm 248.8$ & $114 \pm 236.2$ & 0.5 & \\
\hline
\end{tabular}

CP, Child-Pugh stage; IGF-1, insulin-like growth factor-1; IGF-2, insulin-like growth factor-2; IGFBP-3, insulin-like growth factor binding

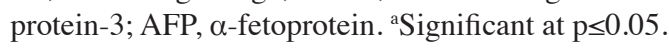

between AFP levels and the levels of IGF-1, 2 and IGFBP-3 in HCC patients.

Serum IGFBP-3 levels are more effective predictors than $I G F-1$ and IGF-2 for the development of HCC in Egyptian patients with cirrhosis. Receiver operating curves (ROC) were used to demonstrate the diagnostic accuracy of IGF-1, IGF-2 and IGFBP-3 individually and in combination in the discrimination between cirrhosis and $\mathrm{HCC}$; and to determine the cut-off values for IGF-1, IGF-2 and IGFBP-3 serum levels for prediction of the development of HCC in Egyptian patients with liver cirrhosis (Fig. 3). The sensitivity, specificity, cut-off value, positive and negative predictive values (PPV, NPV) and diagnostic accuracy for each parameter are shown in Table IV. The areas under the ROC curves (AUC) were 0.78 for IGF1, 0.74 for IGF-2, 0.93 for IGFBP-3 (Fig. 3A), 0.78 for combined IGF-1 and IGF-2 (Fig. 3B), 0.93 for combined IGF-1 and IGFBP-3 (Fig. 3C) and 0.9 for combined IGF-2 and IGFBP-3 (Fig. 3D) (Table IV). These data indicate that IGFBP-3 levels, whether alone or in combination with IGF-1 or IGF-2, had the highest AUC value (0.9-0.93), indicating a higher power to discriminate between HCC and cirrhosis, and, hence a high clinical value. In our study, IGFBP-3 is proposed as a marker for predicting the development of $\mathrm{HCC}$ at an optimal cut-off 
A

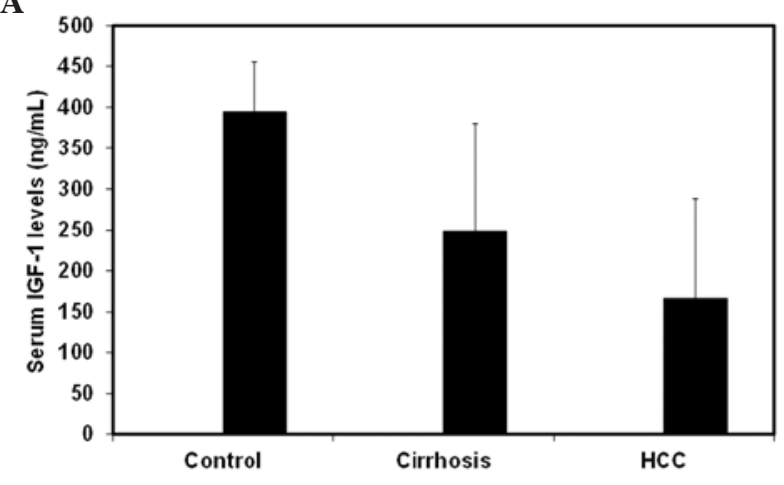

B

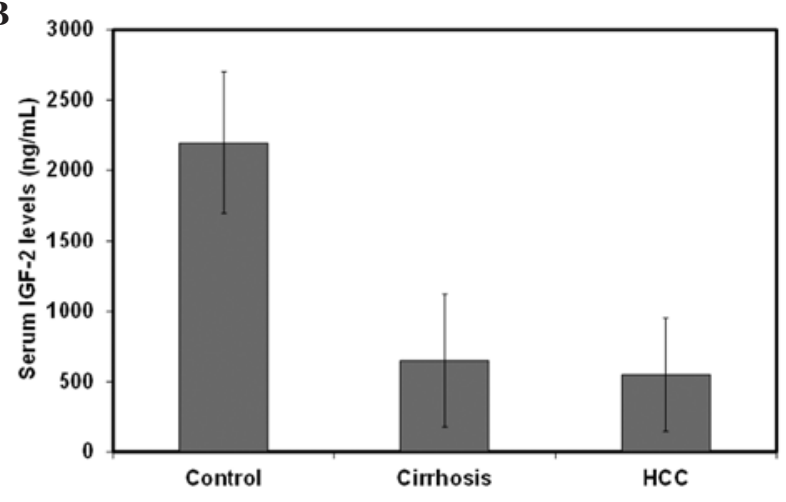

C

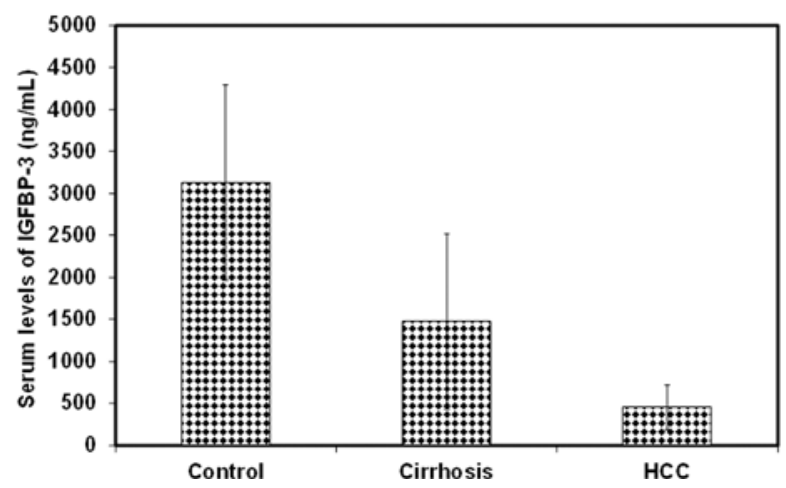

Figure 1. Mean serum levels of (A) IGF-1, (B) IGF-2 and (C) IGFBP-3 decrease in cirrhosis and in HCC patients in comparison to those of healthy subjects.

A

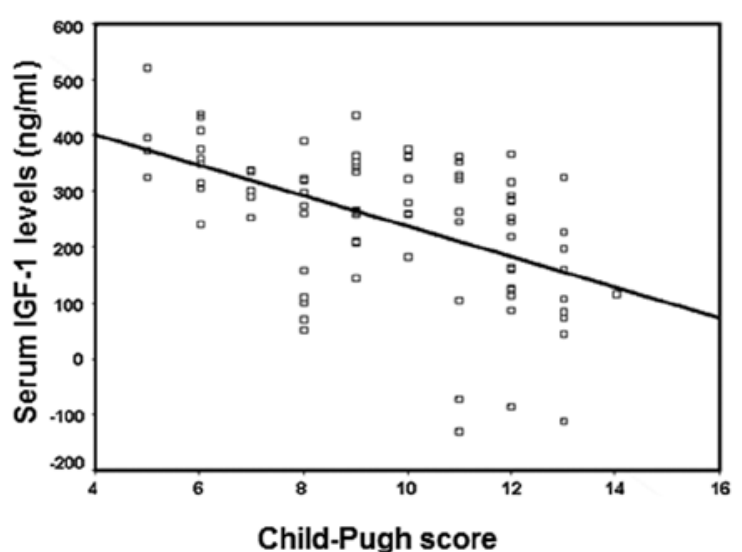

C

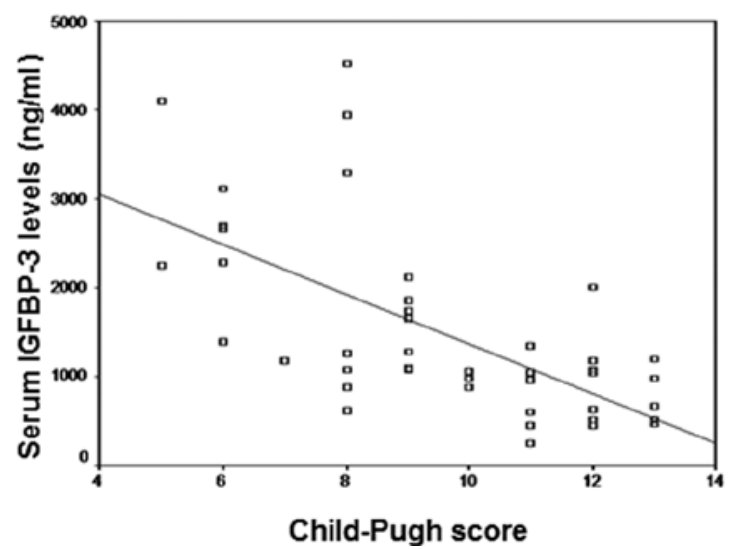

B

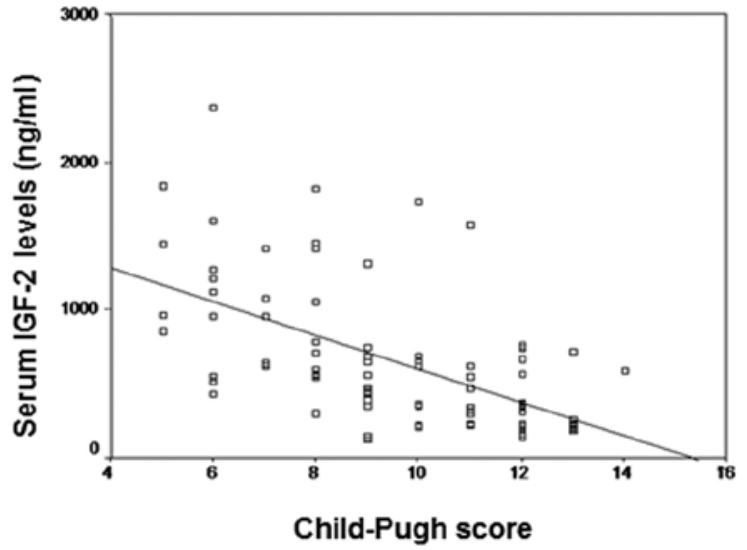

D

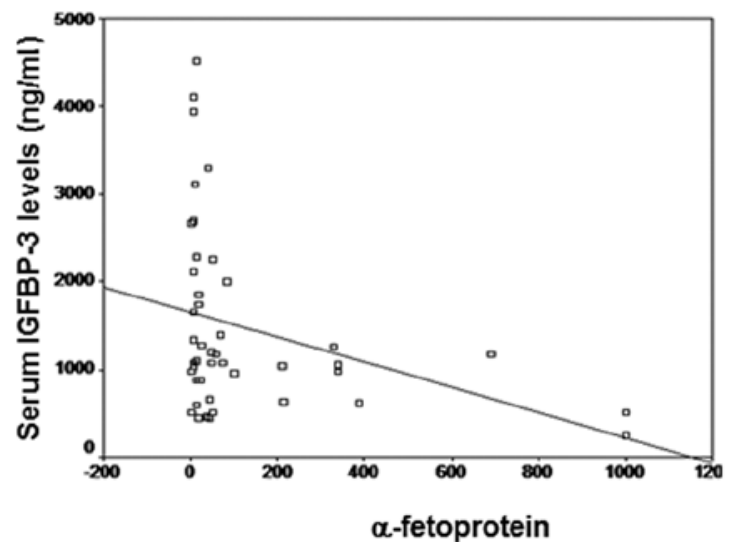

Figure 2. Significant negative correlation between Child-Pugh score and (A) IGF-1, (B) IGF-2 and (C) IGFBP-3 levels in patients with liver cirrhosis (p $\leq 0.05$ ). (D) Significant negative correlation between IGFBP-3 and $\alpha$-fetoprotein (AFP) in patients with liver cirrhosis. 
Table IV. Sensitivity, specificity, diagnostic accuracy, positive and negative predictive values and area under the ROC curves for IGF-1, IGF-2, IGFBP-3 and combinations of two parameters together at the optimal cut-off values.

\begin{tabular}{lccccccc}
\hline & Sensitivity $(\%)$ & Specificity $(\%)$ & Cut-off value & PPV $(\%)$ & NPV $(\%)$ & Diagnostic accuracy $(\%)$ & AUC \\
\hline IGF-1 & 81 & 62 & $<207.4$ & 60.6 & 88.2 & 80.8 & 0.78 \\
IGF-2 & 75 & 60 & $<414.5$ & 49.2 & 83.8 & 74.3 & 0.74 \\
IGFBP-3 & 87 & 80 & $<682.6$ & 78 & 88 & 84.3 & 0.93 \\
IGF-1, & 73 & 84 & $<772$ & 52.4 & 68.3 & 59.1 & 0.78 \\
IGF-2 & 89 & 82 & $<885$ & 81.6 & 82 & 81.9 & 0.93 \\
IGF-1, & 89 & & & & & \\
IGFBP-3 & 86 & 84 & $<1246$ & 80.3 & 79.5 & & 0.90 \\
IGF-2, & 86 & & & & &
\end{tabular}

PPV, positive predictive value; NPV, negative predictive value; AUC, area under the ROC curve; IGF-1, insulin-like growth factor-1; IGF-2, insulin-like growth factor-2; IGFBP-3, insulin-like growth factor binding protein-3.
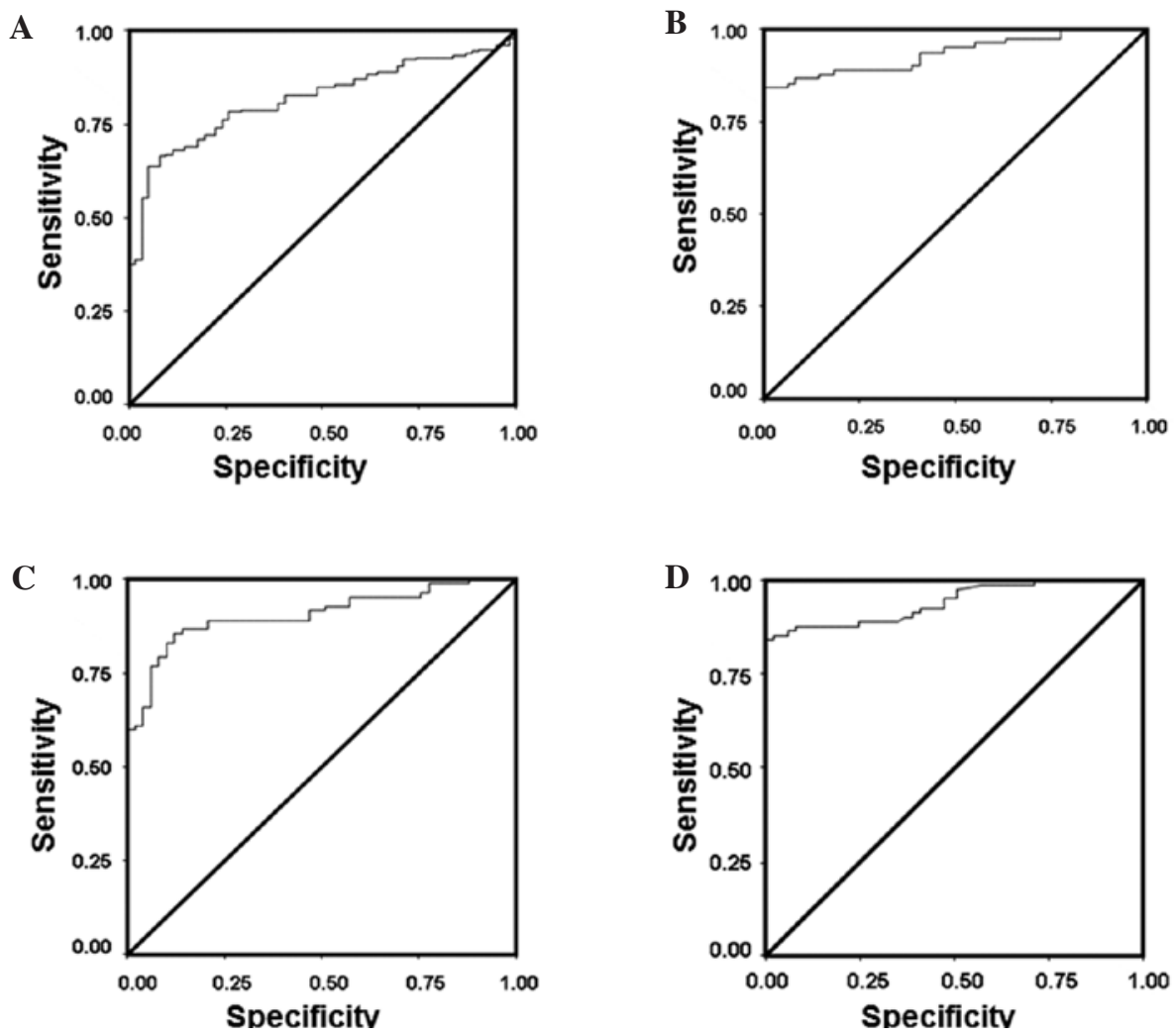

Figure 3. Receiver-operating characteristic (ROC) curves for serum (A) IGFBP-3, (B) IGF-1 and IGF-2, (C) IGF-1 and IGFBP-3 and (D) IGF-2 and IGFBP-3 levels to establish the optimal cut-off values for the prediction of the development of HCC in patients with liver cirrhosis. The areas under the ROC curves are 0.93, 0.78, 0.93 and 0.9 for (A) IGFBP-3, (B) IGF-1 and IGF-2, (C) IGF-1 and IGFBP-3 and (D) IGF-2 and IGFBP-3 levels, respectively.

value of $<682.6$ at $87 \%$ sensitivity and $80 \%$ specificity. The PPV and NPV of IGFBP-3 at the selected cut-off point were 78 and $88 \%$, respectively (Table IV).

\section{Discussion}

In the present study, we investigated the serum levels of IGF-1, IGF-2 and IGFBP-3 in early, intermediate and late stages of cirrhosis, assessed by the $\mathrm{CP}$ score, as well as in $\mathrm{HCC}$ patients. We also studied their correlation with the HCC stage, and with AFP serum levels. In this study, we focused on HCV-induced cirrhosis since the majority of HCC cases in Egypt develop from chronic hepatitis $\mathrm{C}$ infection. We found that serum levels of IGF-1, IGF-2, IGFBP-3 were reduced significantly in cirrhosis and in HCC patients in comparison to the controls. Moreover, the reduction in IGF-1, IGFBP-3, but not IGF-2 
levels was significant in $\mathrm{HCC}$ in comparison to patients with cirrhosis. The reduction in IGF-1, IGF-2 and IGFBP-3 levels negatively correlated with the $\mathrm{CP}$ scores $(\mathrm{A}, \mathrm{B}$ and $\mathrm{C})$ and only IGFBP-3 levels showed a significant negative correlation with AFP levels and a negative correlation with the HCC stage, which was not statistically significant.

In agreement with these results, Aishima et al (20) showed an insignificant negative correlation between HCC staging and serum IGFBP-3 and IGF-1 levels. Moreover, in the present study, IGFBP-3 levels significantly discriminated between cirrhosis and HCC at a sensitivity of $87 \%$, specificity of $80 \%$ and a cut-off value of $<682.6 \mathrm{ng} / \mathrm{ml}$. The PPV and NPV at the optimal IGFBP-3 cut-off value were 78 and $88 \%$, respectively. Experts in risk prediction encourage the use of predictive values to assess the clinical relevance of biomarkers (21). IGF-1 and IGF-2 had an AUC of 0.78 and 0.74 , respectively, and their combined detection did not increase their AUC, sensitivity or specificity. By contrast, when IGFBP-3 values were combined with those of either IGF-1 or IGF-2, their AUCs were increased to 0.93 and 0.9 , respectively, with a concomitant increase in both the sensitivity and specificity. Therefore, concomitant to AFP, IGFBP-3 is a promising marker for the prediction of HCC developing from $\mathrm{HCV}$-cirrhosis in Egyptian patients.

Our results are consistent with several published reports on the serum levels of IGFBP-3 in cirrhosis and in HCC $(15,22-24)$ and in chronic hepatitis prior to developing cirrhosis (25). Furthermore, in HCC patients with or without cirrhosis, IGFBP-3 mRNA levels $(13,26,27)$ and protein levels (28) were lower than those in non-tumor tissues. The decrease in IGFBP-3 mRNA correlated with a tumor-specific IGFBP-3 promoter hypermethylation (26). Findings of other studies have shown that IGFBP-3 protein and IGF-1R were lost or underexpressed in poorly differentiated HCC, but overexpressed in well-differentiated HCC in comparison to normal liver tissue and that IGFBP-3 levels significantly correlated with tumor size, histological differentiation, capsular and portal invasion (20), establishing a role for IGFBP-3 in negatively regulated cell proliferation. The same authors reported that the addition of exogenous IGFBP-3 markedly blocked IGF-1- and IGF-2stimulated proliferation of KYN-2 and HepG2 cells, and also suppressed IGF-1-induced invasion in KYN-2 cells. The results of Aishima et al have shown that the serum levels of IGFBP-3 correlate with the tissue levels of IGFBP-3 protein (20). Thus, in the present study, IGFBP-3 serum levels serve not only as a biomarker for the prediction of hepatic dysfunction and progression towards malignancy, but may have a pathophysiological significance. The molecular mechanism underlying the reduction in serum IGFBP-3 levels in HCV-induced HCC remains to be elucidated. Previous reports demonstrated the association between the hepatitis $\mathrm{B}$ virus oncogenic protein (HBx) modulation of DNA methylation and the downregulation of IGFBP-3 expression in cell lines, animal models and human tumor samples (29). Furthermore, it has been shown that HBx recruits histone deacetylase 1 to repress IGFBP-3 transcription (30). Moreover, IGFBP-3 has been shown to trigger intracellular signalling: Stimulation of phosphotyrosine phosphatase and phosphatidylinositol-3 kinase activities and increase in intracellular calcium (31-33) potentially through its own 'putative' receptor. However, no underlying genetic polymorphisms have been detected in IGFBP-3 to contribute to its downregulation in HCC (34).

In agreement with our results, Wu et al (15) showed a significant reduction of serum IGF-1, IGF-2 and IGFBP-3 levels in patients with cirrhosis compared to controls. Progressive reduction in IGF-2 levels observed in the present study in cirrhosis and in HCC patients are consistent with El-Houseini et al (35). In partial disagreement with our results, a recent study investigated the same parameters in similar patient groups and reported that IGF-2, despite being lower in HCC cases than in healthy controls, was significantly higher compared to patients with liver cirrhosis and, therefore, high serum IGF-2 levels can be used as a tumor marker to discriminate HCC from cirrhosis (36). We did not find a significant difference in the serum levels of IGF-2 in patients with cirrhosis in comparison to those with HCC, and both exhibited lower serum levels than in healthy controls. The differences between those findings and ours may be due to the sample size, as well as the methods used to measure IGF-2. Rehem and El-Shikh (36) conducted their studies on a smaller sample size (60 patients with liver cirrhosis, $20 \mathrm{HCC}$ patients and 20 controls) compared to our sample size (72 patients with liver cirrhosis, $62 \mathrm{HCC}$ patients and 100 healthy controls). It is an established fact that a larger sample size results in better assessment with lower bias. Furthermore, we have used ELISA to measure serum IGF-2 levels, while in the other study radioimmunoassay (RIA) was used (36). Moreover, Rehem and El-Shikh (36) did not report any data concerning the diagnostic accuracy of IGF-1 and IGFBP-3, nor did they demonstrate any significant correlation between IGF-2 and AFP in these cases. However, the authors concluded that IGF-2 and AFP may be used as complementary tumor markers to discriminate $\mathrm{HCC}$ from cirrhosis. In contrast, our analysis of the sensitivity, specificity and diagnostic accuracy of the three IGF members studied revealed that IGFBP-3 was a more effective predictor for the development of HCC than IGF-1 and IGF-2.

Other studies have demonstrated a significant increase in IGF-2 mRNA expression in human cirrhotic liver, in liver cancers and in the peripheral blood of HCC, in human hepatoma cell lines, in comparison to that of normal adult liver (37-40). This discrepancy may be attributed to the fact that in the present study we measured only the free IGF-2 levels in serum but not mRNA. IGF-2 levels may be lower than the mRNA since the bulk of the former is bound to IGFBPs. We believe that serum IGF-2 levels may not be used as a marker for HCC progression, as in our setting IGF-2 had an AUC of 0.74 , whereas it has been previously reported that ROC curves with an AUC $\leq 0.75$ are not clinically useful (41). A comprehensive study by Tovar et al (13) demonstrated overexpression of IGF-2 mRNA resulting from reactivation of the fetal promoters P3 and P4, downregulation of IGFBP-3, allelic loss of IGF-2R and activation of IGF-1R in a specific subclass of human HCC; the 'proliferation' subclass. It is expected that a reduction in the serum levels of IGF-1 and to a lesser extent IGF-2 would occur in cirrhotic liver, since the main pool of circulating IGF-1 is synthesized in liver parenchyma (42), whose mass is greatly reduced in cirrhotic liver, whereas IGFBP-3 is produced by Küpffer, endothelial and hepatic stellate cells, which also synthesize IGF-2 (43-46). Liver damage is apparently not the 
only cause for reduced IGF-1 levels in HCC, as reduced IGF-1 levels were reported in males with HCC without a history of liver cirrhosis and in virus-free metastatic liver cancer $(47,48)$, and did not correlate with the CP score in patients with liver cirrhosis followed up until the development of HCC (11). In the present study, the gradual decrease in circulating IGF-1 levels from HCC precursors to malignancy is consistent with our previous observation, which indicated the initial overexpression of IGF-1R in preneoplastic stages is followed by a gradual decrease and complete loss in HCC in rats (7). Moreover, our findings are in concordance with reports by Huynh et al (28) and Aishima et al (20), who showed lower levels of IGF-1R expression in a significant number of human HCC by immunohistochemistry. Low serum levels of IGF-1 do not prove a specific function of IGF-1 in hepatocarcinogenesis per se, but from this and previous reports from human and experimental hepatocarcinogenesis the following may be speculated: i) the low levels of IGF-1 in cirrhosis and in HCC may be caused by separate events since chronic liver disease is known to be an IGF-1 deficiency state, as reviewed by Bonefeld and Moller (49); however, the cause of low IGF-1 serum levels in HCC patients with no history of cirrhosis remains to be elucidated. ii) IGF-1 may only be required in initiating events of hepatocarcinogenesis; iii) the autocrine and paracrine effects of IGF-1 may be more relevant to cell transformation than its endocrine effect, and iv) IGFBP-3 may have other roles in modulating IGF-1 effects than its binding capacity.

In conclusion, although our results have showm that serum IGF-1, IGF-2 and IGFBP-3 are reduced with the progression of hepatic dysfunction, only IGFBP-3 may be considered as the most promising serological marker for the prediction of the development of HCC in Egyptian chronic HCV patients with liver cirrhosis. Future studies should be directed towards understanding the association between serum and tissue growth factor levels.

\section{Acknowledgements}

The authors are grateful to Professor Abbas Omar, Professor of Clinical Oncology and Nuclear Medicine, Faculty of Medicine, and Dr Hanan Mostafa, lecturer of Internal Medicine, Medical Research Institute, Alexandria University for providing blood samples from HCC patients, and to Ms. Hoda Mabrouk, Faculty of Medicine, Alexandria University for technical assistance. This study was supported by a research grant from the Science and Technology Development Fund (STDF), Egypt (Grant No. 445) to Dr Eiman Aleem.

\section{References}

1. Hsieh PM, Hung KC and Chen YS: Tumor lysis syndrome after transarterial chemoembolization of hepatocellular carcinoma: case reports and literature review. World J Gastroenterol 15 : 4726-4728, 2009.

2. Anwar WA, Khaled HM, Amra HA, El-Nezami H and Loffredo CA: Changing pattern of hepatocellular carcinoma (HCC) and its risk factors in Egypt: possibilities for prevention. Mutat Res 659: 176-184, 2008.

3. Sievert W, Altraif I, Razavi HA, et al: A systematic review of hepatitis C virus epidemiology in Asia, Australia and Egypt. Liver Int 31 Suppl 2: 61-80, 2011.

4. Thorgeirsson SS and Grisham JW: Molecular pathogenesis of human hepatocellular carcinoma. Nat Genet 31: 339-346, 2002.
5. Furstenberger G and Senn HJ: Insulin-like growth factors and cancer. Lancet Oncol 3: 298-302, 2002.

6. Nehrbass D, Klimek F and Bannasch P: Overexpression of insulin receptor substrate-1 emerges early in hepatocarcinogenesis and elicits preneoplastic hepatic glycogenosis. Am J Pathol 152: 341-345, 1998.

7. Aleem E, Nehrbass D, Klimek F, Mayer D and Bannasch P: Upregulation of the insulin receptor and type I insulin-like growth factor receptor are early events in hepatocarcinogenesis. Toxicol Pathol 39: 524-543, 2011.

8. Rosen CJ and Pollak M: Circulating IGF-I: new perspectives for a new century. Trends Endocrinol Metab 10: 136-141, 1999.

9. Rosenfeld RG, Kofoed E, Little B, et al: Growth hormone insensitivity resulting from post-GH receptor defects. Growth Horm IGF Res 14 Suppl A: S35-S38, 2004.

10. Jones JI and Clemmons DR: Insulin-like growth factors and their binding proteins: biological actions. Endocr Rev 16: 3-34, 1995.

11. Mazziotti G, Sorvillo F, Morisco F, et al: Serum insulin-like growth factor I evaluation as a useful tool for predicting the risk of developing hepatocellular carcinoma in patients with hepatitis $C$ virus-related cirrhosis: a prospective study. Cancer 95: 2539-2545, 2002.

12. Su WW, Lee KT, Yeh YT, et al: Association of circulating insulin-like growth factor 1 with hepatocellular carcinoma: one cross-sectional correlation study. J Clin Lab Anal 24: 195-200, 2010.

13. Tovar V, Alsinet C, Villanueva A, et al: IGF activation in a molecular subclass of hepatocellular carcinoma and pre-clinical efficacy of IGF-1R blockage. J Hepatol 52: 550-559, 2010.

14. Sidlova K, Pechova M, Kotaska K and Prusa R: Insulin-like growth factor binding protein-3 in patients with liver cirrhosis Physiol Res 51: 587-590, 2002.

15. Wu YL, Ye J, Zhang S, Zhong J and Xi RP: Clinical significance of serum IGF-I, IGF-II and IGFBP-3 in liver cirrhosis. World J Gastroenterol 10: 2740-2743, 2004.

16. Bruix J and Llovet JM: Hepatocellular carcinoma: is surveillance cost effective? Gut 48: 149-150, 2001.

17. Spangenberg HC, Thimme R and Blum HE: Serum markers of hepatocellular carcinoma. Semin Liver Dis 26: 385-390, 2006.

18. Srinivas PR, Kramer BS and Srivastava S: Trends in biomarker research for cancer detection. Lancet Oncol 2: 698-704, 2001

19. Kato N, Yokosuka O, Omata M, Hosoda K and Ohto M: Detection of hepatitis $\mathrm{C}$ virus ribonucleic acid in the serum by amplification with polymerase chain reaction. J Clin Invest 86: 1764-1767, 1990.

20. Aishima S, Basaki Y, Oda Y, et al: High expression of insulin-like growth factor binding protein-3 is correlated with lower portal invasion and better prognosis in human hepatocellular carcinoma. Cancer Sci 97: 1182-1190, 2006.

21. McShane LM, Altman DG and Sauerbrei W: Identification of clinically useful cancer prognostic factors: what are we missing? J Natl Cancer Inst 97: 1023-1025, 2005.

22. Shaarawy M, Fikry MA, Massoud BA and Lotfy S: Insulin-like growth factor binding protein-3: a novel biomarker for the assessment of the synthetic capacity of hepatocytes in liver cirrhosis. J Clin Endocrinol Metab 83: 3316-3319, 1998

23. Mattera D, Capuano G, Colao A, et al: Increased IGF-I : IGFBP-3 ratio in patients with hepatocellular carcinoma. Clin Endocrinol (Oxf) 59: 699-706, 2003.

24. Elsammak MY, Amin GM, Khalil GM, Ragab WS and Abaza MM: Possible contribution of serum activin A and IGF-1 in the development of hepatocellular carcinoma in Egyptian patients suffering from combined hepatitis $\mathrm{C}$ virus infection and hepatic schistosomiasis. Clin Biochem 39: 623-629, 2006.

25. Okan A, Comlekci A, Akpinar H et al: Serum concentrations of insulin-like growth factor-I and insulin-like growth factor binding protein-3 in patients with chronic hepatitis. Scand J Gastroenterol 35: 1212-1215, 2000.

26. Hanafusa T, Yumoto Y, Nouso K, et al: Reduced expression of insulin-like growth factor binding protein-3 and its promoter hypermethylation in human hepatocellular carcinoma. Cancer Lett 176: 149-158, 2002.

27. Luo SM, Tan WM, Deng WX, Zhuang SM and Luo JW: Expression of albumin, IGF-1, IGFBP-3 in tumor tissues and adjacent non-tumor tissues of hepatocellular carcinoma patients with cirrhosis. World J Gastroenterol 11: 4272-4276, 2005.

28. Huynh H, Chow PK, Ooi LL and Soo KC: A possible role for insulin-like growth factor-binding protein-3 autocrine/paracrine loops in controlling hepatocellular carcinoma cell proliferation. Cell Growth Differ 13: 115-122, 2002. 
29. Park IY, Sohn BH, Yu E, et al: Aberrant epigenetic modification in hepatocarcinogenesis induced by hepatitis B virus $\mathrm{X}$ protein. Gastroenterology 132: 1476-1494, 2007.

30. Shon JK, Shon BH, Park IY, et al: Hepatitis B virus-X protein recruits histone deacetylase 1 to repress insulin-like growth factor binding protein 3 transcription. Virus Res 139: 14-21, 2009.

31. Ricort JM, Lombet A, Lassarre C and Binoux M: Insulin-like growth factor binding protein-3 increases intracellular calcium concentrations in MCF-7 breast carcinoma cells. FEBS Lett 527: 293-297, 2002

32. Ricort JM and Binoux M: Insulin-like growth factor-binding protein-3 activates a phosphotyrosine phosphatase. Effects on the insulin-like growth factor signaling pathway. J Biol Chem 277: 19448-19454, 2002.

33. Ricort JM and Binoux M: Insulin-like growth factor binding protein-3 stimulates phosphatidylinositol 3-kinase in MCF-7 breast carcinoma cells. Biochem Biophys Res Commun 314 1044-1049, 2004.

34. Weng CJ, Hsieh YH, Tsai CM, et al: Relationship of insulin-like growth factors system gene polymorphisms with the susceptibility and pathological development of hepatocellular carcinoma. Ann Surg Oncol 17: 1808-1815, 2010.

35. El-Houseini ME, Mohammed MS, Elshemey WM, Hussein TD, Desouky OS and Elsayed AA: Enhanced detection of hepatocellular carcinoma. Cancer Control 12: 248-253, 2005.

36. Rehem RN and El-Shikh WM: Serum IGF-1, IGF-2 and IGFBP-3 as parameters in the assessment of liver dysfunction in patients with hepatic cirrhosis and in the diagnosis of hepatocellular carcinoma. Hepato-gastroenterology 58: 949-954, 2011.

37. Scharf JG, Ramadori G and Dombrowski F: Analysis of the IGF axis in preneoplastic hepatic foci and hepatocellular neoplasms developing after low-number pancreatic islet transplantation into the livers of streptozotocin diabetic rats. Lab Invest 80: 1399-1411, 2000.

38. Price JA, Kovach SJ, Johnson T, et al: Insulin-like growth factor I is a comitogen for hepatocyte growth factor in a rat model of hepatocellular carcinoma. Hepatology 36: 1089-1097, 2002.

39. Qian J, Yao D, Dong Z, et al: Characteristics of hepatic IGF-ii expression and monitored levels of circulating IGF-ii mRNA in metastasis of hepatocellular carcinoma. Am J Clin Pathol 134: 799-806, 2010.
40. El Tayebi HM, Salah W, El Sayed IH et al: Expression of insulinlike growth factor-II, matrix metalloproteinases, and their tissue inhibitors as predictive markers in the peripheral blood of HCC patients. Biomarkers 16: 346-354, 2011

41. Fan J, Upadhye S and Worster A: Understanding receiver operating characteristic (ROC) curves. CJEM 8: 19-20, 2006

42. Scott CD, Martin JL and Baxter RC: Production of insulin-like growth factor I and its binding protein by adult rat hepatocytes in primary culture. Endocrinology 116: 1094-1101, 1985.

43. Chin E, Zhou J, Dai J, Baxter RC and Bondy CA: Cellular localization and regulation of gene expression for components of the insulin-like growth factor ternary binding protein complex. Endocrinology 134: 2498-2504, 1994.

44. Villafuerte BC, Koop BL, Pao CI, Gu L, Birdsong GG and Phillips LS: Coculture of primary rat hepatocytes and nonparenchymal cells permits expression of insulin-like growth factor binding protein-3 in vitro. Endocrinology 134: 2044-2050, 1994.

45. Scharf J, Ramadori G, Braulke T and Hartmann H: Synthesis of insulinlike growth factor binding proteins and of the acid-labile subunit in primary cultures of rat hepatocytes, of Kupffer cells, and in cocultures: regulation by insulin, insulinlike growth factor, and growth hormone. Hepatology 23: 818-827, 1996.

46. Scharf JG, Schmidt-Sandte W, Pahernik SA, Ramadori G, Braulke $\mathrm{T}$ and Hartmann $\mathrm{H}$ : Characterization of the insulin-like growth factor axis in a human hepatoma cell line (PLC). Carcinogenesis 19: 2121-2128, 1998.

47. Stuver SO, Kuper H, Tzonou A, et al: Insulin-like growth factor 1 in hepatocellular carcinoma and metastatic liver cancer in men. Int J Cancer 87: 118-121, 2000.

48. Major JM, Stolzenberg-Solomon RZ, Pollak MN, Snyder K, Virtamo J and Albanes D: Insulin-like growth factors and liver cancer risk in male smokers. Br J Cancer 103: 1089-1092, 2010.

49. Bonefeld $\mathrm{K}$ and Moller S: Insulin-like growth factor-I and the liver. Liver Int 31: 911-919, 2011. 